\section{Prototyping and innovating}

'Some of the power is in the "what-if ?" prototyping and understanding correlations between data and assets. It is not about creating a commercial product in the first instance, but understanding the relationships and whether there could be a value in the information, then looking at how to turn it into an industrial grade product. There is an opportunity to look at areas on which we haven't had information before and whether there is any benefit', he said.

Both the ODI and IDM are innovating in their own right and mutually, through the new Open Data for Marketers training programme, which has been jointly developed and will run in early 2014. The course will run first at the ODI in January and then again in March at the IDM and is aimed at both client side and agency practitioners, entrepreneurs and start-ups, policymakers and strategists. It will educate participants about the differences between open, closed and personal data, the opportunities and benefits of open data, together with the potential Return on Investment. Issues around licensing and intellectual property will be addressed, plus how to find, assess and use open data sets. Both the ODI and IDM will contribute case studies and best practice examples to make this the most valuable course on the subject for marketing professionals.

If such projects bring together the commercial muscle of existing data users and service providers with the innovative drive of the start-ups, it could help to transform the data industry.

David Reed FIDM

\title{
DataIQ Future Summit 2013 - Conference review
}

Trends in technology, business and society

Missing meals to buy
phone credits
Journal of Direct, Data and Digital Marketing Practice (2013) 15, 169-175. doi:10.1057/dddmp.2013.51

DataIQ's annual Future Summit has become a fixture in the conference calendar since it launched 3 years ago. Unlike other events that focus narrowly on marketing or business strategy, what differentiates the summit, which ran on 15 October 2013, is the way it looks at a range of trends across technology, business and society and seeks to identify which will have the biggest impact.

Author Tom Chatfield opened the event by pointing out that the most important technology in history has been writing since it has allowed ideas to propagate. 'Writing is data that endures after death. In ancient Egypt, there was a death penalty for trying to write without being a licenced scribe. That meant a few were being employed on the behalf of the many, so we have no view of people beyond the official record', he said.

That situation endured until as recently as 75 years ago when mass literacy led to over half of the world's population being able to write and therefore to record their personal data. The last decade has seen a yet 


\section{Embracing structured loss of control}

\section{Technology is like a knife}

'Just because you can,
doesn't mean you do' more remarkable shift through the adoption of the mobile phone. Chatfield noted that, in some developing countries, 'people will miss a meal in order to buy credit for their phone, while among American teenagers, 50 per cent of their waking time is spent consuming media'.

While this means we now have visibility of every user of a mobile phone and on the internet, the transformation many expected has not happened. 'The worry used to be that technology would usurp humanity that didn't happen', said Chatfield. Neither did many of the improvements that were anticipated. 'We could have had Utopia, but we would rather tweet'.

Twitter has become a conversation without speech and one that can be reinterpreted far beyond its original intention, as a number of high-profile people have found to their cost when casually retweeting. Chatfield noted that this is a very new phenomenon in human communication and is an indicator of a 'structured loss of control'. Rather than resisting this shift, however, he challenged delegates to embrace it.

As an example of the visibility we now have of consumer behaviour and its unintended consequences, the study carried out by Michal Kosinski is a perfect example. As deputy director of the Cambridge Psychometrics Centre, he analysed Facebook likes and was able to predict a range of personal and lifestyle characteristics from this simple variable to a surprisingly high degree of accuracy.

In many ways, this just replicates the selling skills that car salesmen have long demonstrated. 'The practical problem is how to use those to sell on a wider scale. That has changed with big data - consumers are leaving a digital footprint that provides information about their goals and motivations', said Kosinski.

Although this has troubled commentators in the media - his predictive models generated over one hundred stories - he believes the reality is more nuanced. 'There are risks, but also amazing opportunities technology is morally neutral. We can use it to improve life or to harm ourselves - just like a knife', he said.

In the wave of digital data now crashing over marketers, it can be easy to lose sight of what Colin Grieves, director of strategy and propositions, data and analytics, Experian Marketing Services - headline sponsors of the DataIQ Future Summit - described as 'old data. It is still important because it drives the business. For example, if you understand the demographics of your customers you can look at how many other people there are who look like that'. Event triggers may also be as powerful as behavioural indicators, such as births, deaths and marriages, he argued.

'In the four-year buying cycle for a car, for example, understanding when somebody is in market is valuable, so picking up likes for a car brand on Facebook is useful', said Grieves. Behavioural indicators from social media or search terms are even more effective if combined with conventional data sets. 'All that data can now be applied consistently across channels if you can link an email address with a Facebook identity', he said.

He also sounded a warning about the potential 'creepiness' that use of this data in the wrong way could lead to. 'Just because you can, doesn't mean you do. You need to be aware of not making it scary', said Grieves. 


\section{'Consumers don't think about channels'}

\section{Data protection fines not related to harm}

\section{Businesses unable to quantify spending on data protection}

The issue of what data to use in communicating with customers was clearly revealed in a presentation by Claire Chandler, head of customer marketing at Nectar. With 19 million collectors on its loyalty programme, 'customers have high expectations - if we collect data, they want it to be used. If we ask for information, they want to see it played back. That sets the bar high', she said.

The company has introduced its own voluntary code of practice called TACT, standing for Trust, Added value, Control and Transparency. New data sets that may be matchable against its existing collector records 'open up opportunities', noted Chandler, but she pointed out that many of the new channels that yield this data are currently very expensive.

'Some media is still not one-to-one, so what you can do is still some way behind the times. There are opportunities at segment level, but that dilutes the message', she noted. Conversely, the more personalized and intimate channels do present challenges around processing and compliance. Even so, collectors do not view the market this way. 'Consumers don't think about channels - marketers do that. To them, it is just about engagement with the brand and they think that should be consistent', she said.

Those difficulties around cost and compliance are likely to increase as and when Brussels finally approves a new Data Protection Regulation. It had seemed as if the DataIQ Future Summit might be dominated by discussions of the new law, but as it turned out delays in reaching agreement on a final version had created a strange sense of calm about the potential new legal framework.

Even so, there was a good opportunity to understand what the original proposals might mean for businesses in the session given by Moritz Godel, associate director at London Economics. His organization had been commissioned by the Information Commissioner's Office to examine the cost implications of the Regulation.

He started his presentation by noting that more data is likely to fall under the category of 'personally identifiable information' and that the proposed levels of sanctions for breaching the new law are independent of any actual harm that has been caused. (Subsequent to the event, the leading version of the Regulation was approved with fines set at 5 per cent of global turnover, not 2 per cent, which had already been considered excessive.)

Godel outlined the main areas of cost that are likely to result, from managing access rights through to appointing a data protection officer. Some of these costs will be one-offs, while others will be ongoing. In launching the Regulation, Brussels had claimed it would save European businesses $€ 2.3 \mathrm{bn}$, whereas in the United Kingdom, the Ministry of Justice has said it will cost UK companies between $£ 80 \mathrm{~m}$ and $£ 320 \mathrm{~m}$ per year. Separately, the DMA has put a figure of $£ 76,000$ per year for every SME to meet the new demands.

That demonstrates just how challenging it had been for London Economics to establish the possible cost base. 'Up to 80 per cent of companies we spoke to are unable to quantify their current spending on data protection', said Godel. 'That probably reflects a lack of clarity around the term. Those companies gaining a high benefit from data do spend a lot on it'. 


\section{Mobile advertising on upward trajectory}

\section{Timing and length impact on mobile ad performance}

Godel suggested that the costs of appointing a data protection officer may not turn out to be as high as suggested, especially for large organizations, as they either already have one in place or currently employ a potential DPO. 'Most cost estimates do not take into account existing provisions for compliance', he noted. Even so, he added that: 'The impact on business is likely to be profound through its potential to limit what business and do with data. There are some in the European Parliament who want to do exactly that'.

A late change to the agenda introduced James Hanscombe, head of insight at Weve, the joint venture between $\mathrm{O} 2$, Vodafone and $\mathrm{EE}$ and a chance to find out about the cutting edge of marketing in this emerging channel. He started by reflecting on Godel's presentation with the view that, 'there is a risk of data protection being made by people who don't understand data and who intend to protect consumers, so they end up doing it in a very blanket way'.

Hanscombe started by pointing to a few key trends, such as 70 per cent of mobile handsets now being smartphones and consumers using their phones to make purchases while looking at products on the High Street (often called 'show rooming').

But he noted that, 'mobile advertising is still in its infancy. However, if you look at the way digital advertising grew from nothing to take 20 per cent of all ad spend, mobile is following the same trajectory in a shorter time frame'. He predicted it will achieve $£ 1$ bn spend next year, double what it took in the previous 12 months. 'That is what is needed to pull in proper brands and advertisers now that a lot of the groundwork has been done', he said.

A key shift with mobile advertising is to target by audience, rather than by publisher. Hanscombe showed an example from the launch of the Windows Phone aiming at 25- to 45-year-old mums and dads who had an early smartphone. Weve was able to identify them in its 20 million optedin database and send a message that linked through to a demonstration page giving a sense of what the experience would be like. A click-through rate of 3 per cent was achieved.

One of the insights he shared with delegates was the importance of getting the timing right in a campaign. 'We have done research across all the campaigns we have run which shows that $3 \mathrm{pm}$ on Thursday is the best time over all - subscribers are six times more likely to respond compared to 10am on a Tuesday', he said. Equally, a message of less than 240 characters will get twice the level of response, while a message over 320 characters long will drive three times the level of opt out.

Frequency capping is an important business rule for Weve as it has discovered that subscribers who are sent a message every day for 4 days are 50 per cent more likely to opt out. 'We self regulate and do less than one message per day because we can't afford that opt out rate', said Hanscombe.

Interestingly, Weve has run successful tests to try to build the five major personality types out of its own data, without having looked at the robust academic framework for this (as presented earlier by Kosinski). 'I have tried to do that with different types of data over the last 15 years without 
Three streams of content

\section{Transformation at Channel 4}

\section{Five benefits of connected viewers}

success. The way people use their mobile is so personal and predictive that we can use it to target advertising to them when they are "in the moment" , said Hanscombe.

Following these sessions in the first half of the summit, delegates could choose between presentations organized into three streams: 'The Customer 2014', featuring Holly Mander of Teradata eCircle on integrating the customer experience, David Reed, editor of DataIQ, debriefing research into big data and analytics and Iain Lovatt of Blue Sheep, looking at money mapping customers; 'The CMO's Technology Toolkit', with Ed Ballard of RAPP looking at the connected customer, Martin Smith of Neolane and Claire Kavanagh of giffgaff providing a case study of customer engagement technology and Henry Lawson of nFluence covering consumer control in the mobile channel; 'Data Governance', featuring Angus Sim of Callcredit Information Services on trust in the digital economy, John Kitchen of Royal Mail on the Enterprise Intelligent Barcode programme and Christine Andrews of DQM Group and James Mullock of Osborne Clarke on data capability.

The final section of the event opened with an example of genuine business transformation through the use of data. Gill Whitehead, director of Audience Technology and Insight at Channel 4, explained how the broadcaster is changing as a result of the data it is collecting on the 'connected viewer'.

'Broadcasting has always been one-to-many, whether via terrestrial, satellite or cable via a "dumb box". We had little idea about the viewer. That has changed - the main TV set is increasingly connected and viewers are using other connected devices', she said. A counter-intuitive result of the growing number of access devices in households is that TV viewing has actually increased, she pointed out, with an average of over 4 hours daily. Ad revenues have also held stable and are forecast to rise 3 per cent in 2014, while subscription payments for pay-TV services are generating new sources of income.

Change is starting to happen at high speed, ushering in an era of one-toone broadcasting for the first time. For Channel 4, this started 2 years ago when it began to offer new ways to access content through its online portal, creating an opportunity for data capture. 'Transparency was key and we approached that very carefully. We have a viewer promise, which is fronted by Alan Carr, that has allowed us to build trust with our audience. So now we have nine million registered viewers', Whitehead told the conference.

That base includes one-third of all 16- to 20-year-olds in the United Kingdom, giving the channel significant coverage of a very hard-to-reach segment. As with all viewers, Channel 4 is now able to match that firstparty data with viewing behaviour and access device across channels to create a very rich picture of its audience.

Whitehead outlined five benefits of this transformation:

1. Stimulating viewing: 'Evidence shows that by making contact, 46 per cent watch more', said Whitehead.

2. Relationship marketing: Channel 4 sent 40 million emails in 2012 and has seen open rates rise by 25 per cent and click-throughs to promoted 


\section{Five drivers of the Age of Context}

content double. The viewer response has been, 'OMG, you remembered!', when the broadcaster has sent messages about a new season of a viewer's favourite show, for example.

3. Responding to viewer behaviour: Over 3 months, the channel sees four million unique visitors to its site, while five million visit less often but tend to watch via the live TV stream.

4. Audience insight: Youth audiences have been segmented within the Tribe Live stream online to reflect the differences between groups and to allow them to moderate their own conversations. 'That is allowing us to understand youth culture and sub-cultures. We have opened that to advertisers who want to get their views', she explained.

5. Ad trading: 'We went clients and agencies to understand how to use data to innovate on how TV is traded - it has been done the same way for a long time', said Whitehead. A trial with a handful of advertisers has focused on picking out specific targets within the on-demand viewer base in real time. By doing this, one client was able to make its ad packages 40 per cent more efficient. 'We will be taking that to market at scale and believe half of advertising will become tradable via targeted audiences', said Whitehead.

As she noted, the future of TV is being shaped by data. The broadcasting industry is not alone in trying to transform itself, but as Thomas Power, head of communities at Google+Networks, pointed out: 'Very bright people find it hard to succeed because it's complicated'.

He examined five key drivers that are setting the pace of change in 'The Age of Context'. The first of these is mobile, with the average consumer lifting their handset to their face 150 times a day, he reported. The second is big data, closely followed by the third, physical location. As an example of how that may transform industries, he discussed a start-up called FlightCar, which allows individuals to rent out their cars while they are away on holiday or business. It breaks even on the rental service and makes its profits by selling the data to other service providers at airports.

'What does Hertz or Avis do about that? Does it acquire the business, kill it or partner?' he wondered. The fourth driver of change is sensors, which are multiplying in number in vehicles, mobile phones and even paper. 'Soon you won't be able to lose anything', said Power. The final force is social media, which many CEOs hate, not least because they lack the skills to use it effectively. With Facebook reaching 1.4 billion users - more than all the visitors to every Google service combined - a real tussle is forecast for ownership of the online consumer.

The combination of these trends is likely to be that "products will become very highly personalised and everything will be tracked', said Power. 'Can brands become competent at using all that data? How comfortable will people be in allowing technology to run their lives? We are already slaves to technology — why not let it become the best tool it can be?' That may include the much-heralded self-driving car, for example. 


\section{'Technology has become the prison, not the release'}

\section{Leadership, not management}

The big picture of where these technology trends are taking both society and business was provided in the day's final session. Dave Coplin, chief envisioning officer at Microsoft UK, started by pointing out that "what Star Trek teaches you as a kid is that technology is a force for good. It is supposed to enable us to live beyond our potential and to be greater than the sum of our parts'.

But he added: 'With twenty years of experience in the IT industry and seeing how people use technology, I can see it has become the prison, not the release. The problem is us'. In the work environment, technology now lags behind what many have on offer at home and yet it is still treated as 'special'. As a result, 71 per cent of the US workforce is disengaged, Coplin pointed out. 'We can't afford that we have to find a better way'.

This is not a new problem - the Industrial Revolution ushered in an approach to work that was focused on an atomized process, rather than on its outcome. It was accompanied by a very rigid management hierarchy. 'Offices tie people to a specific piece of technology in a single location being managed and held back by that technology', he said.

Human brains do not work creatively in this environment as they need the opportunity for deep thought in a state of 'flow'. This takes on average 15 minutes to achieve but, as Coplin pointed out, 'how often do you get that long without interruption or distraction? It doesn't happen in open plan offices'. A prime example of the problem is email, which has become 'a bucket for digital conversations' and non-important content. 'In that environment, working smarter is not an option. The only way is to work harder - and I refuse to accept that. We need to re-imagine business'.

Creating the social business is one way to transform this model, starting with the adoption of social media to share information. This should unlock collaboration by making information freer and more widely distributed, rather than reserved and kept as a political asset by executives. 'It is the power of the network that changes the way business works', said Coplin. 'We need to create organisms, not organisations which are unable to respond quickly. That is about leadership, not management, which is a fundamental shift'.

It will be brave companies that decide to recognize this trend and adapt to it early, especially in a phase where major employers such as Yahoo! and Hewlett-Packard have both just rescinded their home-working policies. The potential of the technology now available to support such new models is undoubted, as are the downside risks if the data it generates is not carefully handled. The DataIQ Future Summit provided much to consider and some very strong indicators of what the world might look like within a few short years. 